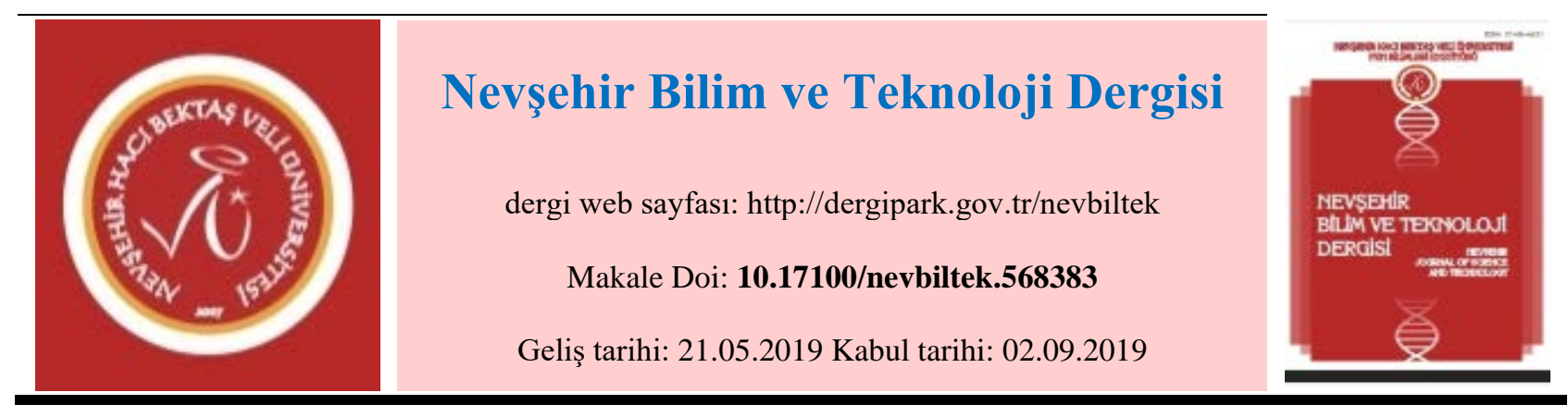

\title{
Peyzaj Mimarlığında Minimalist Yaklaşımlar ve Tasarım Kriterleri
}

\author{
M. Akif IRMAK ${ }^{1,}$, Cihad BİLGE ${ }^{2}$ \\ ${ }^{1}$ Atatürk Üniversitesi, Mimarlık ve Tasarım Fakültesi, Peyzaj Mimarlı̆̆ı Bölümü, Erzurum \\ ORCID ID: https://orcid.org/0000-0001-8285-5341 \\ ${ }^{2}$ Atatürk Üniversitesi, Mimarlık ve Tasarım Fakültesi, Peyzaj Mimarlı̆̆ Bölümü, Erzurum \\ ORCID ID: https://orcid.org/0000-0002-9949-3452
}

\section{Özet}

Minimalizm, 1960 sonrası Post-Modern Dönem akımı olup, Fransızca kökenli olan "minimum” anlamına gelen “minimal” sözcüğünden türetilmiştir. Bir ihtiyaç veya birey için gerekli olan en az veya en küçük miktar olarak tanımlanmaktadır. Minimalizm, sadeliği ve nesnel yaklaşımı savunan bir akımdır. Sanatta ve mimaride sadelik, basitlik ve azlık kavramlarını öne çıkarmakta, kullanılan materyali minumuma indirgemektedir. Bunun nedeni modernizmin sonucu olarak gerçekleşen ve yaygınlaşan teknolojinin toplum üzerinde oluşturduğu, yoğun, sıkıcı kalabalığı, mental yorgunluğu ve stresi dağıtmaktır. Minimalizm akımının sadelik, basitlik, azlık kavramlarını ve indirgeyici yaklaşımını öne çıkarması, mimarlık ve peyzaj mimarlığında etkili olmuş ve son dönemlerde tasarımcıların minimalist tasarımlara yoğunlaşmasına neden olmuştur. Çağdaş peyzaj mimarlığında, minimalizm akımının etkileri özellikle 1960’lı yıllardan sonra görülmeye başlanmıştır. Minimalizm akımı peyzaj mimarlığından sadelik, basitlik ve azlık kavramını ön plana çıkarırken, basit geometrik biçimlere ve saf renklere yer vermiştir. Minimalist tasarımlarda sadelikte bütünlük ve mükemmeliyetçilik anlayışı hâkimdir. Bu çalışma kapsamında minimalizm ve minimalist tasarım anlayışına Peyzaj Mimarlığı açısından bakılarak, temel kriterler ortaya konulmuştur. Bu kapsamda Türkiye dışında 13 farklı ülke ve 30'a yakın şehirden değişik dönemlerde incelenmiş peyzaj alanlarından minimalist tasarım özelliği gösteren tasarımlar örneklenmiştir. Ayrıca Türkiye’de çeşitli kentlerden incelenmiş peyzaj tasarımları üzerinde minimalizm kriterleri ortaya konulmuştur. Amacı en az malzeme ile en sade, en ekonomik ve en işlevsel sonucun ortaya konulması olan minimalist tasarımların peyzaj çalışmalarında; bitki kullanımında, sert zemin uygulamalarında, donatı seçiminde ve tasarım sınırlarının belirlenmesindeki temel kriterleri değerlendirilmiştir. Minimalist tasarım anlayışının peyzaj çalışmalarında getirdiği yenilikler ve faydalı yönler üzerinde durulmuştur.

Anahtar Kelimeler: Minimalizm, Minimalist Peyzaj, Minimalist Tasarım, Minimalist Yaklaşımlar, Peyzaj Tasarım

\section{Minimalist Approaches and Design Criteria in Landscape Architecture}

\begin{abstract}
Minimalism is post-modern period post-1960, which originated in French. It is derived from the word "minimal” meaning "minimum”. It is defined as the minimum or minimum amount required for a requirement or individual. .Minimalism, a movement that advocates simplicity and objective approach. In art and architecture, simplicity, simplicity and scarcity bring forth the concepts and minimize the material used. The reason for this is to distribute the intense, boring crowds, mental fatigue and stress that the technology that is becoming widespread as a result of modernism is creating on the society. The concept of minimalism, simplicity, scarcity and reductionist approach of the current has been effective in architecture and Landscape Architecture, and recently has caused designers to concentrate on minimalist designs. In contemporary landscape architecture, the effects of minimalism have been seen especially since the 1960s. While the minimalism current highlights the concept of simplicity, simplicity and scarcity from landscape architecture, it includes simple geometric shapes and pure colors. In minimalist designs, the understanding of integrity and excellence is dominant. Within the scope of this study, basic criteria have been laid by considering the minimalism and minimalist design approach in terms of Landscape Architecture.
\end{abstract}


In this context, designs showing minimalist designs from 13 different countries in Turkey and more than 30 cities have been examined in different periods. In addition, criteria for minimalism have been laid on Landscape Designs examined from various cities in Turkey. The basic criteria for the landscape studies of minimalist designs whose aim is to present the most basic, economic and functional results with the least material; plant use, hard ground applications, reinforcement selection and design limits were evaluated. The concept of minimalist design has been focused on the new and useful aspects of Landscape Studies

Keywords: Minimalism, Minimalist Landscape, Minimalist Design, Minimalist Approaches, Landscape Design

\section{Giriş}

20.Yüzyılın başlarına kadar var olan süreçteki sanatsal faaliyetler, Geleneksel Sanat Akımları olarak bilinirken, 20. yüzyılın başlarından itibaren Modernizm (Çağdaş Sanat Akımları) adı altında büyük değişiklikler yaşamıştır. II. Dünya Savaşı’ndan sonrası ise Post-Modernizm olarak bilinmektedir.

Postmodern düşünce, modernizm hareketinin bir uzantısı niteliğinde gündeme gelerek sanatta ve mimarlıkta etkisini göstermiştir. Bu düşüncenin etkisi peyzaj mimarlığında da görülmeye başlanmıştır. Modern dönemden farklı tasarım yaklaşımlarını içeren ve 1970’lerden sonra etkisini gösteren bir anlayıştır. Peyzaj mimarlığında postmodernizm; 1960’lardan sonra etkili olan minimalizm, pop-art, dekonstrüktivizm, kavramsal sanat ve arazi sanatı gibi akımlar postmodern hareketin içinde yer almaktadır. Bu akımların yanı sıra postmodernizmde gündelik olanı estetikleştiren ve tarihsel stildeki bazı uygulamaları içeren tasarım yaklaşımları da görülmektedir [1].

Postmodern akımlardan özellikle 1960 sonrası etkili olan minimalizmi incelediğimizde; "Minimalizm” sözcüğü, Fransızca kökenli olup "minimum” anlamına gelen "minimal” sözcüğünden türemiştir. Kelimenin sözlük anlamı "Bir ihtiyaç veya birey için gerekli olan en az veya en küçük miktar (derece, nicelik)" olarak tanımlanırken; matematikteki ifadesi “değişken bir niceliğin inebildiği en alt basamak, asgari, minimal” şeklindedir. Minimalizm, De Stijl, Bauhaus ve Uluslar Arası Üslup/Stil akımlarında yer alan basitlik ve azlık akımıyla gerçekleşmiştir [2].

Minimalizm, 1960’lı yılların sonlarında görsel sanatlar ve müzikte ortaya çıkmıştır. Aşırı sadeliği ve nesnel yaklaşımı savunan bir akımdır. Sanatta sadelik, basitlik ve azlık kavramlarını öne çıkarmaktadır [3].

Görsel sanatlar, müzik, edebiyat, felsefe, eğitim teknikleri, bilgisayar yazılımları ve mimaride kendini gösteren bu akımın temel özelliği materyali minimuma indirmektir. Çok az kişi kendini minimalist olarak tanımlasa da teknikleri, çeşitli ve geniş bir alanda kullanılarak uygulanmıştır [4].

"Minimalizm” terimi, ilk kez, 1965 yılında Richard Wolheim tarafından kullanılmıştır. Birkaç sınırlı rengin kullanıldığı büyük monokrom renk alanları olarak ortaya çıkan ve yalın, geometrik tasarıma sahip minimalist resim; nesnelerin ruhsal doğasına vurgu yapar ve izleyicinin bu ruhsal doğayı anlayıp cevap verdiğini savunur. Amerika'daki bu gelişmeler bir süre sonra Avrupa'da da yer bulmuştur [5].

Minimalist tasarımlarda görsel izlenim uyandırmak amacıyla sert kenarlara, geometrik, büyük, basit biçimlere yer verilmiştir [3]. Bir kare, dikdörtgen ya da dairenin temel formalarının izleyicide kaçınılmaz olarak belirli duygular doğurduğuna inanılır [1].

Minimalizm önce kendini kabullendirmiş daha sonra ise renk ve biçim açısından uygulanan indirgemeci tavır ile farklı bir yere doğru kaymaya başlamıştır. Kökten olmasa da bu ciddi bir değişim olarak kabul edilir. Bu değişimin sebebi modernizmin sonucu olarak gerçekleşen ve zamanla yaygınlaşan teknolojinin oluşturduğu, yoğunlaşan sıkıcı kalabalığı dağıtmaktı. Bu yoğunluk toplumun mental olarak yorulmasına ve stres dolmasına zemin oluşturmaktadır. Bu nedenle kendi doğal renk ve dokularına müdahale gerektirmeyen; ahşap, beton, çelik, demir gibi hazır endüstri ürünü malzemeler kullanmaya başlanmıştır [6]. 
Dönemlere göre incelediğimizde, minimalzim Tablo 1'de görüldüğü gibi 1960 ve sonras1 post-modern hareketinin ürünüdür.

Tablo 1. Dönemlere Göre Sanat Akımları [7].

\begin{tabular}{|c|c|c|c|c|}
\hline \multirow{10}{*}{ (2) } & \multirow{10}{*}{\multicolumn{2}{|c|}{ 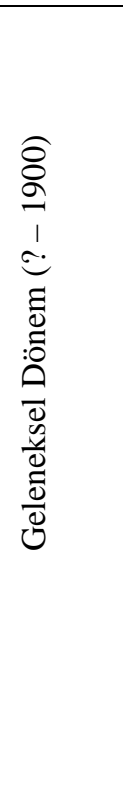 }} & DÖNEM & SANAT AKIMLARI \\
\hline & & & Eskiçağ & $\begin{array}{l}\text { Misır Sanatı } \\
\text { Mezopotamya Sanatı } \\
\text { Ege ve Yunan Medeniyetlerine ait Sanat Özellikleri }\end{array}$ \\
\hline & & & Ortaçağ & Ortaçağ Sanatı \\
\hline & & & Ortaçağ & Bizans Sanatı \\
\hline & & & 7. Yüzyıl & İslam Medeniyetlerine Ait Sanat Özellikler \\
\hline & & & 15.-16. Yüzy1l & Rönesans Sanatı \\
\hline & & & $\begin{array}{lll} & 1520-1600 & \text { Y1llar1 } \\
\text { Aras1 } & & \\
\end{array}$ & Maniyerizm \\
\hline & & & 16-17-18. Yüzyılları & Barok Sanatı \\
\hline & & & 18. Yüzyıl & Naturalizm Akımı, Çin ve Japon Sanatı \\
\hline & & & 19. Yüzyıl & Endüstri Çağı ve Sanayi Devrimi \\
\hline$\frac{\tilde{E}}{\overbrace{0}^{\circ}}$ & : & 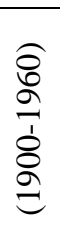 & $\begin{array}{l}\text { 20. Yüzy1l } \\
(1900-1960)\end{array}$ & $\begin{array}{l}\text { Art Nouveau, Fovizm, Pürizm, Fütürizm, Ekspresyonizm, } \\
\text { Kübizm, Empresyonizm, Sembolizm, Sürrealizm, } \\
\text { Konstrüktizim, Biyofrizm, Soyut Sanat, Sosyal Gerçeklik, } \\
\text { Art Deco Akımı, Dadaizm, De Stijl Akımı, Fovizm }\end{array}$ \\
\hline$\sum_{\substack{0 \\
0}}^{0}$ & : & 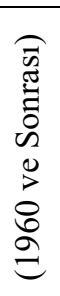 & 1960 ve Sonras 1 & $\begin{array}{l}\text { Soyut Dışavurumculuk, Pop Sanatı, Ham Sanat, Olay } \\
\text { Sanatı, Arazi Sanatı, Çevresel Sanat, Minimalizm, } \\
\text { Hiperrealizm, Video Sanatı, Kavramsal Sanat, } \\
\text { Dekonstrüktivizm, Metobolizm Hareketi, Public art., } \\
\text { Optic Art (Op art) }\end{array}$ \\
\hline
\end{tabular}

Peyzaj mimarlığı açısından dönemleri incelediğimizde, 20. yüzyılın başlarına kadar geleneksel stiller etkili olmuştur. Bu dönemde daha çok natüralist ve pitoresk stil ile formal ya da informal tasarımlar uygulanmıştır.

20. yüzyılın başlarında ise sanatta ve mimarlıkta gelenekselliğin dışına çıkan hatta bu gelenekselliği tamamiyle reddeden, ögzünlüğe dayalı modernizm yaklaşımları meydana gelmiştir. 1920'lerden sonra baskın bir şekilde peyzaj mimarlı̆̆ında modern yani çağdaş dönem başlamıştır.

Bilimsel ve teknik aşamaların yanında peyzaj tasarımlarında işlevsel ve mekânsal çözümler sunulmuş ve teknolojiden yararlanılarak yeni malzemelerin kullanımı sağlanmıştır. Bu süreçle insan yaşam doyumu da göz önünde bulundurularak, çevreye duyarlı ve ekolojik yaklaşımlar gerçekleştirilmiştir [1].

Minimalizm akımı peyzaj mimarlığından sadelik, basitlik ve azlık kavramını ön plana çıkarırken, basit geometrik biçimlere ve saf renklere yer vermiştir. Tasarımlara bir mana yüklememiş veya eklememiştir. Sadelikte bütünlük ve mükemmeliyetçilik anlayışı hâkimdir.

Peyzaj mimarlığında minimalizm, yaşamımızda meydana gelen birtakım zor geçişler yoluyla bize öncülük eden ve bize aydınlatan sorunları kısmen açığa çıkarmaktadır. Bunlar sadeleştirme, zanaat kaybı, geleneksel doğal maddeden yapay maddeye geçiş ve insan ölçeğinin hem yer hem zaman bakımından mekanik olarak kolaylaştırılmış 
modern yaşamın büyük çaplı ölçeğine genişlemesidir. Bu bağlamda minimalizm şu anda da yüzleştiğimiz en önemli çevre problemlerinden dev atıklar ve azalan kaynaklara karşı sanatsal ve başarılı bir akım İleri sürmektedir [8], [1].

Mimar Mies van der Rohe, minimalizm akımının temellerini atan "Less is More” yani “Az çoktur.” sloganıyla sadeliğin daha etkileyici olduğunu belirtmiştir. Peyzaj mimarlığında minimalizmin amacı, en az malzemeyle, en sade, en ekonomik aynı zamanda en işlevsel sonucu ortaya koymaktır [2].

Peyzaj mimarlığında minimalizm akımının etkileri Peter Walker ve Martha Schwartz'ın peyzaj tasarımlarında görülmektedir. Schwartz ve Walker minimal peyzaj tasarımlarında alanı ızgaralara oturtarak tasarlanmış ve sert peyzajlar kullanmışlardır. Minimalist peyzaj tasarımında pratik kullanımda eksiklikler olsa da etkileyiciliğin itici gücünü taşımaktadır [1 ve 9].

Peter Walker, Minimalist tasarım anlayışıyla ilgili prensipler olarak 'hareket, sert ve düzgün yüzeyler ve akıcılık’ kavramlarını kullanmıştır [10].

"Minimalizmin temel özellikleri” şu şekilde sıralanmaktadır [4]:

- $\quad$ Kesin, birimsel geometrik formlar,

- $\quad$ Sabit ve genellikle hareket değişikliğinden yoksun -bazen tek renkli- renk yüzeyler,

- $\quad$ Birim ve birimin tekrarıyla; hiyerarşisiz, matematiksel düzenliliğe sahip kompozisyonlar,

- $\quad$ Tüm diş gönderme ve metaforlardan uzaklaşma.

Yapılan bu çalışma kapsamında, minimalizm ve minimalist tasarım anlayışına peyzaj mimarlığı açısından bakılarak, temel kriterler ortaya konulmuştur. Amacı en az malzeme ile en sade, en ekonomik ve en işlevsel sonucun ortaya konulması olan minimalist tasarımların peyzaj çalışmalarında; bitki kullanımında, sert zemin uygulamalarında, donatı seçiminde ve tasarım sınırlarının belirlenmesindeki temel kriterleri değerlendirilmiştir. Minimalist tasarım anlayışının peyzaj çalışmalarında getirdiği yenilikler ve faydalı yönler üzerinde durulmuştur.

\section{Materyal ve Metot}

Çalışmanın materyalini, Türkiye dışında 13 farklı ülke ve 30'a yakın şehirden değişik dönemlerde incelenmiş peyzaj alanlarından alınan fotoğraflar ve Türkiye'de çeşitli kentlerden incelenmiş peyzaj tasarımları ile görsel sanatlar ve mimaride minimalist olarak tasarımı yapılmış olan çalışmalar oluşturmaktadır. Bu örnekler üzerinden, peyzaj mimarlı̆̆ında minimalist tasarım kriterleri oluşturulmuştur.

Çalışma kapsamında öncelikli olarak minimalizm akımının temel felsefesi, özellikleri, mimarideki ve görsel sanatlardaki güncel durumu ve kriterleri ortaya konulmuştur. Daha sonra minimalist akım kapsamında yapılmış olan tasarımlar incelenmiştir. Son aşamada ise; değişik ülkelerde yapılmış arazi incelemeleri sonucunda, peyzaj mimarlığı açısından minimalist tasarım olabilecek özellik taşıyan tasarımların ortak özellikleri belirlenerek, bu sanat akımının peyzaj mimarlığı disiplininde temel kriterleri belirlenmiştir.

Bu kapsamda özellikle görsel sanatlarda minimalist tasarım üzerinde duran; [3], [4], [5], [6], [11], [12], [13], [14], [15], [16], [17] kaynaklarından ve peyzaj alanında minimalist yaklaşım üzerinde çalışan [1], [2], [7], [8], [9] ve [10] literatürlerinden faydalanılmıştır. 


\section{Bulgular}

Yapılan literatür çalışması sonucunda görsel sanatlar ve mimari minimalizmde; denge, form, renk, ritm, sadelik ve boşluk kavramları ön plana çıkmaktadır. Peyzaj mimarlığı açısından bu kavramlar; konstrüktsiyon, plantasyon ve tasarımsal işlev yani fonksiyon açısından her biri birer kriterdir.

\section{Denge Açısından Minimalizm}

Minimalistlerde büyük boyutlu, yalın ve ritmik hareketlerle oluşan devinimle birlikte bütünselliğin, simetri ve düzenin bir sonucu olarak dengeyi izlemekteyiz. Minimalistler, yapıtlarını tasarlarken belli öğeler arasındaki dengeyle sağlanan kompozisyon kaygısından da vazgeçmişler, öğelerin dizisel tekrarına dayalı simetrik bir düzenle sağlanan bütünlüğe önem vermişler, Gestaltvari bir parça-bütün ilişkisi gözetmişlerdir [12].

\section{Form (Yüzey) Açısından Minimalizm}

Minimalistler, bir kare, dikdörtgen ya da dairenin temel formlarını izleyicide kaçınılmaz olarak belirli duygular ve etkiler doğurduğuna inanmaktadırlar [16].

Gerçek mekânı kullanmak, espasın kendi içinde olmak, boyanın yüzey üzerinde yarattığı mekân yanılsamasından, yani espas duygusundan çok daha heyecan verici olduğu, minimalistlerce genel bir kabuldür [12].

Donald Judd 1965 yılında; “Resim ya da heykel olmayan bu üç-boyutlu yapıtlara 'spesifik nesne' diyerek bir tanım getirmiş, Minimalist yapıtları resim ve heykelden ayırmıştır [16].

\section{Renk Açısından Minimalizm}

Yüzeyin sadeliğinden ve tek rengin hâkim olduğu renk alanlarından etkilenmişlerdir. Minimalizm'de tonlama yoktur. Minimal Sanat'ın yalın, düşünsel ve mimarlıkla bütünleşen görünümü ortaya çıkmıştır [14].

\section{Ritm Açısından Minimalizm}

Ritm kavramının, sanat yapıtında en çok kullanıldığı akımlardan biri ninimalizm olmuştur. Minimalistler hem iki boyutlu hem de üç boyutlu yapıtlarında ritmi yaygın bir şekilde kullanmışlardır [13].

\section{Biçim Açısından Minimalizm}

Minimalistler de konstrüktivistler gibi biçime işlevsellik yüklerler. Minimaller biçimi yalınlaştırmışlardır. Yalınlaşan sanat anlayışı ile biçim daha çok etkili ve güçlü kendini hissettirmektedir.

Minimalizmde amaç en basit ifade yollarına, en basit bileşenlere indirgenerek bir tür kolay anlaşılır sanata ulaşmaktır. $\mathrm{Bu}$ durumda minimalizm çok kuvvetlidir; çünkü rengin, biçimin en etkili hali bulunup ortaya çıkartılmaktadır [11].

Biçimsel sadeliği olan minimalistler kullandıkları biçimleri hazır-nesnelerden oluşturmaktadır. Minimalist sanatçıların hazır-nesnelerle oluşturdukları kompozisyonlarda biçimsel farklılıklar kendini açık bir şekilde gösterir. Minimalistler eserlerini her türlü simgesel ve göndergesel ögelerden arındırarak, doğadaki nesneleri temsil etmeyen biçimler yaratmak çabasındadırlar [15].

\section{Boşluk Açısından Minimalizm}

Aralıkların ve ölçümlerin bir sanat eseri için önemi olabilir. Bazı aralıklar önemliyse, bunlar yapıtta açıkça vurgulanmalıdır. Eğer boşluk görece daha az önem taşıyorsa, düzenlenmeli ve eşitlenmeli (yani elemanlar eşit aralıklarla yerleştirilmeli); aşırı göze batan boşluklar daha makul hale getirilerek yumuşatılmalıdır [17].

Türkiye dışında 13 farklı ülke ve 30'a yakın şehirden değişik dönemlerde incelenmiş peyzaj alanlarından alınan fotoğraflar ve Türkiye’de çeşitli kentlerden incelenmiş peyzaj tasarımları ile görsel sanatlar ve mimaride minimalist olarak tasarımı yapılmış olan çalışmalar ve bunların incelenmesi Tablo 2.'de gösterilmiştir. 
Tablo 2. Çeşitli Kentlerden İncelenmiş Peyzaj Tasarımları İle Görsel Sanatlar ve Mimaride Minimalist Olarak Tasarımı Yapılmış Olan Çalışmalar ve Bunların İncelenmesi [18], [19], [20], 21], [22], [23], [24]. (Türkiye dışında verilen tüm fotoğraflar yazarlar tarafından çekilmiştir.)

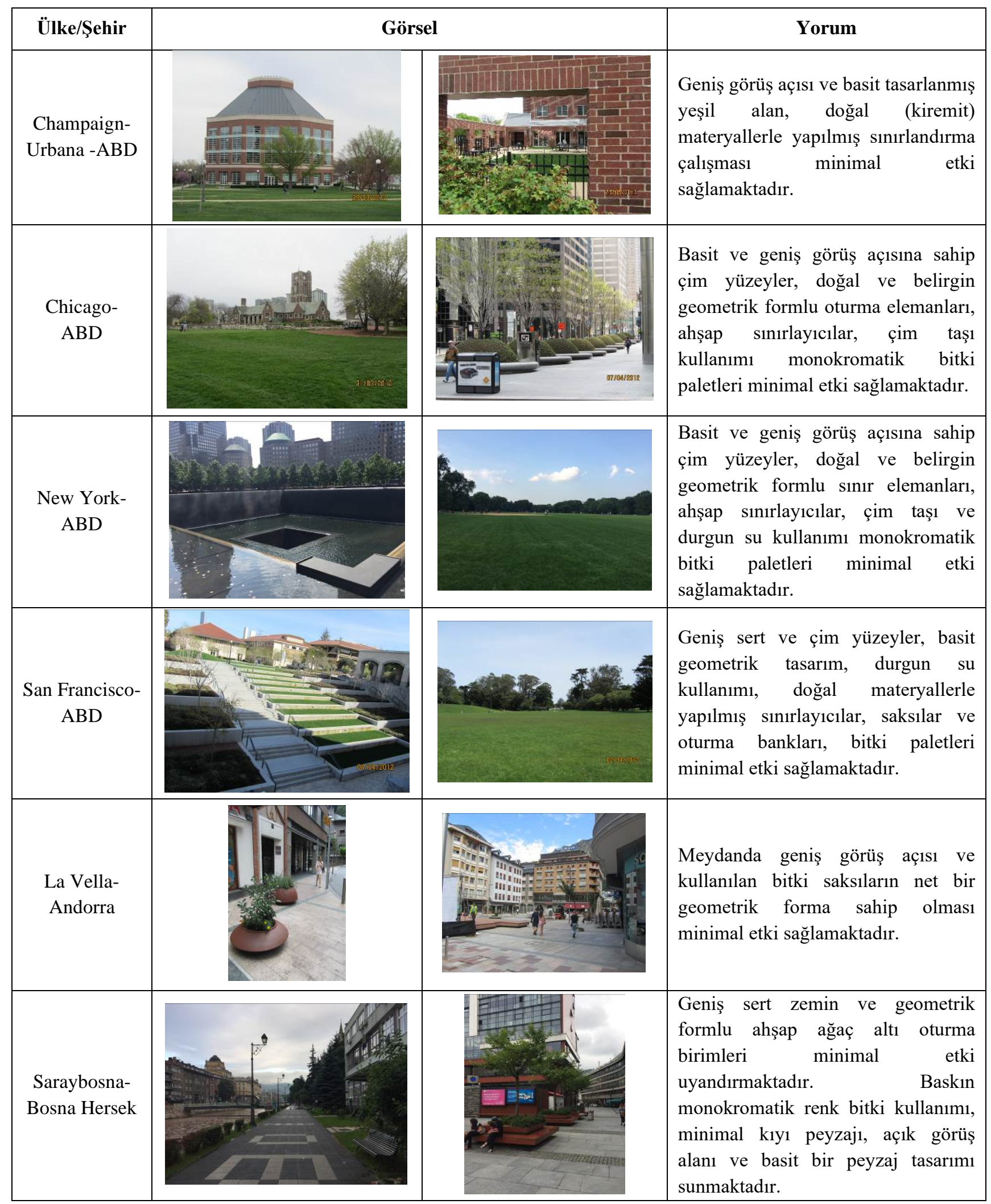




\begin{tabular}{|c|c|c|c|}
\hline $\begin{array}{l}\text { Prag- } \\
\text { Çekya }\end{array}$ & 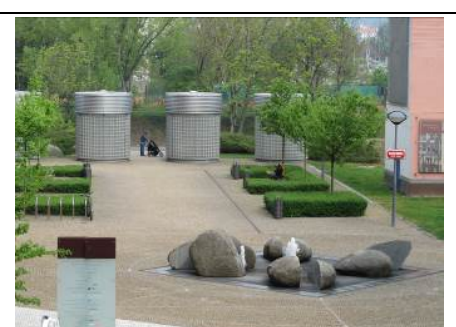 & $\frac{\min }{2}$ & $\begin{array}{l}\text { Geniş sert ve çim yüzeyler, basit } \\
\text { geometrik tasarım, doğal } \\
\text { materyallerle yapılmış sınırlayıcılar } \\
\text { ve oturma bankları, bitki paletleri, } \\
\text { durgun su yüzeyleri minimal etki } \\
\text { sağlamaktadır. }\end{array}$ \\
\hline $\begin{array}{l}\text { Cannes } \\
\text { Fransa }\end{array}$ & & (2) & $\begin{array}{l}\text { Bitkilerle geometrik form verilerek } \\
\text { sınırlandırma çalışması yapılmıştır. } \\
\text { Kuraklığa dayanıklı bitki kullanımı, } \\
\text { doğal taş ile sınırlandırma çalışması } \\
\text { ve sakin su kullanımıyla minimalist } \\
\text { tasarım sağlanmıştır. }\end{array}$ \\
\hline $\begin{array}{l}\text { Nice- } \\
\text { Fransa }\end{array}$ & 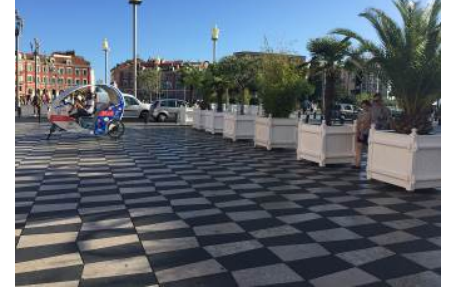 & $13<3<$ & $\begin{array}{l}\text { Basit ve geniş görüş açısına sahip } \\
\text { sert yüzeyler, belirgin geometrik } \\
\text { formlu sert zemin döşemesi, } \\
\text { monokromatik bitki paletleri ve bitki } \\
\text { saksıları minimal etki sağlamaktadır. }\end{array}$ \\
\hline $\begin{array}{l}\text { Paris- } \\
\text { Fransa }\end{array}$ & & Atringin & $\begin{array}{l}\text { Basit ve geniş görüş açısına sahip } \\
\text { çim yüzeyler, monokromatik bitki } \\
\text { paletleri ve ahşap bitki saksıları } \\
\text { minimal etki sağlamaktadır. }\end{array}$ \\
\hline $\begin{array}{l}\text { Dubrovnik- } \\
\text { Hirvatistan }\end{array}$ & 3 & Dili -4 & $\begin{array}{l}\text { Büyük taç yapısına sahip tijli, } \\
\text { monokromatik renkli bitki kullanımı, } \\
\text { doğal sınırlayıcılar, sakin su } \\
\text { kullanımı, bitki saksıları, minimal } \\
\text { etki sağlamaktadır. }\end{array}$ \\
\hline $\begin{array}{l}\text { Cockington- } \\
\text { İngiltere }\end{array}$ & & & $\begin{array}{l}\text { Geniş çim yüzey alanları, } \\
\text { monokromatik renkli bitki kullanımı, } \\
\text { doğal sınırlayıcılar, durgun su } \\
\text { kullanımı } \\
\text { sağlamaktadır. }\end{array}$ \\
\hline $\begin{array}{l}\text { Dawlish- } \\
\text { İngiltere }\end{array}$ & 28 & $x^{2}$ & $\begin{array}{l}\text { Geniş çim yüzey alanları, dominant } \\
\text { olarak monokromatik renkli bitki } \\
\text { kullanımı, doğal sınırlayıcılar, } \\
\text { durgun su kullanımı minimal etki } \\
\text { sağlamaktadır. }\end{array}$ \\
\hline
\end{tabular}




\begin{tabular}{|c|c|c|c|}
\hline $\begin{array}{l}\text { Exeter- } \\
\text { Ingiltere }\end{array}$ & the & 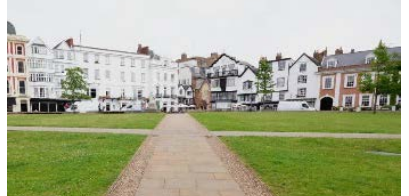 & $\begin{array}{l}\text { Geniş çim yüzey alanları, dominant } \\
\text { olarak monokromatik renkli bitki } \\
\text { kullanımı, basit tasarım minimal etki } \\
\text { sağlamaktadır. }\end{array}$ \\
\hline $\begin{array}{l}\text { Londra- } \\
\text { İngiltere }\end{array}$ & & 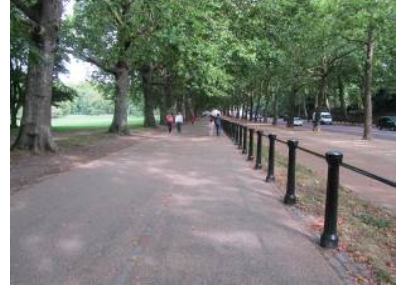 & $\begin{array}{l}\text { Geniş sert ve çim(dominant) } \\
\text { yüzeyler, basit geometrik tasarım, } \\
\text { doğal materyallerle yapılmış } \\
\text { sınırlayıcılar, tijli ve sinırlı sayıa } \\
\text { kullanılan ağaçlar minimal etki } \\
\text { sağlamaktadır. }\end{array}$ \\
\hline $\begin{array}{l}\text { Paington- } \\
\text { İngiltere }\end{array}$ & 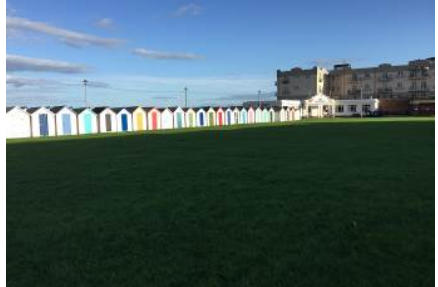 & 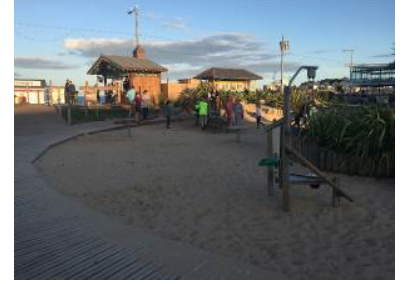 & $\begin{array}{l}\text { Basit ve geniş görüş açısına sahip } \\
\text { çim yüzeyler, doğal ve belirgin } \\
\text { geometrik formlu ahşap } \\
\text { sinırlayıcılar, lata zemin ve } \\
\text { monokromatik bitki paletleri } \\
\text { minimal etki sağlamaktadır. }\end{array}$ \\
\hline $\begin{array}{l}\text { Playmouth- } \\
\text { İngiltere }\end{array}$ & & & $\begin{array}{l}\text { Basit tasarım ve geniş görüş açısına } \\
\text { sahip çim yüzey doğal bir kıyı } \\
\text { peyzajı imkanı } \text { ile etkisini } \\
\text { güçlendirerek } \\
\begin{array}{l}\text { sağlamaktadır. } \\
\text { minimal }\end{array}\end{array}$ \\
\hline $\begin{array}{l}\text { Teightmouth- } \\
\text { İngiltere }\end{array}$ & Fing & & $\begin{array}{l}\text { Basit tasarım ve geniş görüş açısına } \\
\text { sahip çım yüzey ve sert zeminler ile } \\
\text { minimal etki sağlamaktadır. }\end{array}$ \\
\hline $\begin{array}{l}\text { Torquay- } \\
\text { İngiltere }\end{array}$ & & $\frac{1}{1-2} v^{2}$ & $\begin{array}{l}\text { Basit tasarım ve geniş görüş açısına } \\
\text { sahip çim yüzey ve sert zeminler ile } \\
\text { geometrik oturma bankları ile } \\
\text { minimal etki sağlanmıştır. }\end{array}$ \\
\hline $\begin{array}{l}\text { Barcelona- } \\
\text { İspanya }\end{array}$ & & & $\begin{array}{l}\text { Geniş görüş açısı ve monokromatik } \\
\text { renk hakim alan. Dar bir alanda } \\
\text { doğal (ahşap) saksı ve doğal } \\
\text { (kiremit) sınırlayıcılar minimal etki } \\
\text { uyandırmaktadır. }\end{array}$ \\
\hline
\end{tabular}




\begin{tabular}{|c|c|c|c|}
\hline $\begin{array}{l}\text { Göteborg- } \\
\text { İsveç }\end{array}$ & 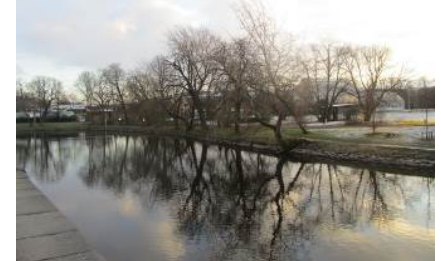 & 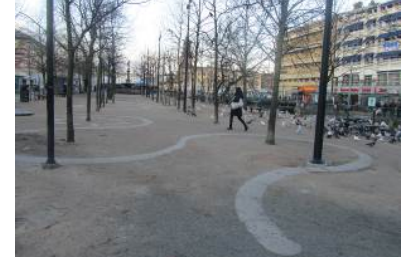 & $\begin{array}{l}\text { Geniş sert yüzey, basit tasarım, doğal } \\
\text { materyallerle yapılmış sınırlayıcılar } \\
\text { ve oturma bankları, sakin su } \\
\text { kullanımı, minimal } \\
\text { sağlamaktadır. }\end{array}$ \\
\hline $\begin{array}{l}\text { Stockholm- } \\
\text { İsveç }\end{array}$ & & & $\begin{array}{l}\text { Geniş sert zemin, geometrik formlu } \\
\text { saksı ve oturma bankları ile minimal } \\
\text { etki sağlanmaktadır. }\end{array}$ \\
\hline $\begin{array}{l}\text { Milano- } \\
\text { İtalya }\end{array}$ & 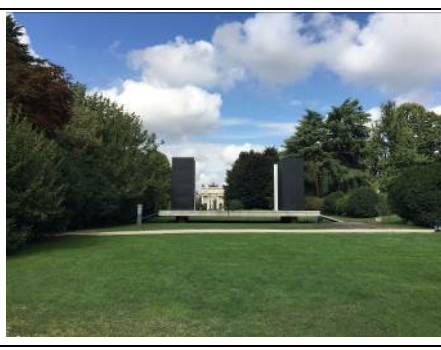 & ह & $\begin{array}{l}\text { Basit ve geniş görüş açısına sahip } \\
\text { çim yüzeyler, doğal ve belirgin } \\
\text { geometrik formlu sınır elemanları, } \\
\text { ahşap sınırlayıcılar, çim taşı ve } \\
\text { durgun su kullanımı monokromatik } \\
\text { bitki paletleri minimal etki } \\
\text { sağlamaktadır. }\end{array}$ \\
\hline $\begin{array}{l}\text { Padova- } \\
\text { İtalya }\end{array}$ & & & $\begin{array}{l}\text { Geniş sert ve çim yüzeyler, basit } \\
\text { geometrik tasarım, durgun su } \\
\text { kullanımı, doğal materyallerle } \\
\text { yapılmış sınırlayıcılar, saksılar ve } \\
\text { oturma bankları, bitki paletleri } \\
\text { minimal etki sağlamaktadır. }\end{array}$ \\
\hline $\begin{array}{l}\text { Bergen- } \\
\text { Norveç }\end{array}$ & 18 & $25 \sin ^{\circ}$ & $\begin{array}{l}\text { Geniş görüş açısı, sert zemin } \\
\text { hâkimiyeti, durgun su kullanımı. } \\
\text { Geometrik form kullanımı ve yüksek } \\
\text { kottan akan sakin su kullanımı } \\
\text { minimal etki uyandırmaktadır. }\end{array}$ \\
\hline $\begin{array}{l}\text { Oslo- } \\
\text { Norveç }\end{array}$ & 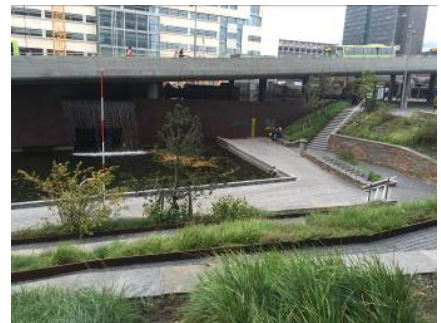 & 1 & $\begin{array}{l}\text { Geniş sert ve çim yüzeyler, basit } \\
\text { geometrik tasarım, durgun su } \\
\text { kullanımı, doğal materyallerle } \\
\text { yapılmış sınırlayıcılar, saksılar ve } \\
\text { oturma bankları, bitki paletleri } \\
\text { minimal etki sağlamaktadır. }\end{array}$ \\
\hline $\begin{array}{l}\text { Adana- } \\
\text { Türkiye }\end{array}$ & & Whe & $\begin{array}{l}\text { Geniş çim yüzeyler, basit geometrik } \\
\text { tasarım, doğal materyallerle yapılmış } \\
\text { sınırlayıcılar, saksılar, oturma } \\
\text { bankları ve bitki paletleri minimal } \\
\text { etki sağlamaktadır. }\end{array}$ \\
\hline
\end{tabular}




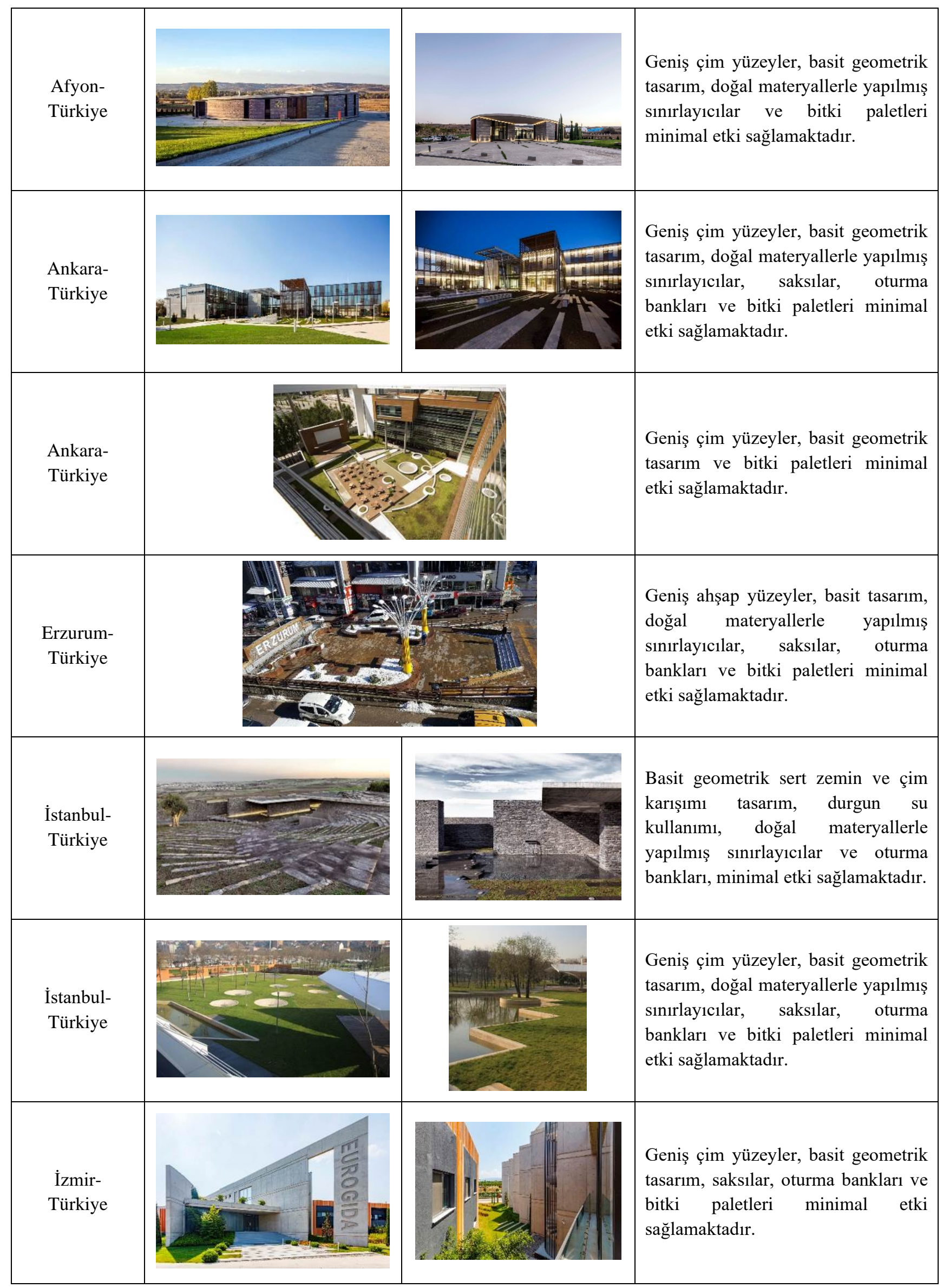




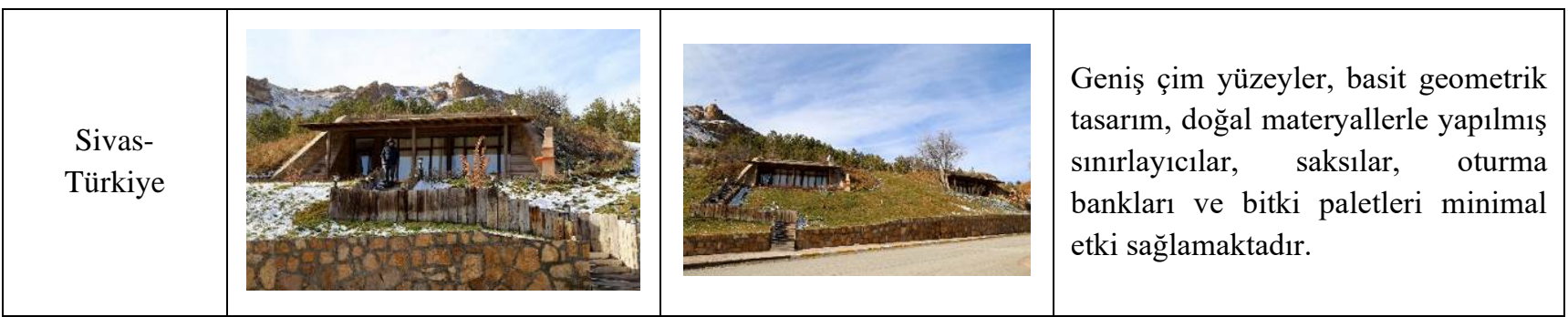

\section{Tartışma ve Sonuç}

Minimalist bahçe tasarımında mekân ve mekânın kullanımı etkilidir. Mimarideki ve iç mimarideki eğilimler dikkate alınarak, sert peyzaj malzemeleri ve bitkilerle; sınırlı, cesur ve basit çizgiler, kullanarak bir mekân oluşturulmaktadır.

\section{1 - Sinırların Ayarlanması}

Bahçede minimalizm sınırla başlar. Kısıtlı renk kullanımından dolayı çitler, duvarlar vb. şeylerin seçimi başarılı bir plan oluşturmakta hayati önem taşır. Duvarlarda kireçtaşı bloklarının kullanılması basit ve minimalist bir sınır oluşturmak için en iyi çözüm olabilir. Duvarların büyüklüğü ve pürüzsüz yüzeyi bir film ekranı olarak ya da bahçenin aydınlatması için katkı sağlar. Sınırlarda, nötr renkler (siyah-beyaz-gri), yatıştırıcı, sade ve popülaritesi yüksek olan bu renkler kullanılabilir. Bazen de boyanmamış, galvanizli, oluklu metal paneller kullanılabilir. Bu panellerin dokularındaki doğal oyuklar gölge meydana getirerek bahçeye farklı bir hava kazandırabilir.

\section{2 - Sinırlı Mazlemeler}

Kullanılacak malzemelerin temiz ve basit bir görünüm elde etmek için malzeme sayısının ve kullanılacak renklerin sınırlanması önemlidir. Örneğin; çitlerde kullanılan bir ahşap materyali yer döşemesinde de kullanarak, ikincil bir malzemeye gerek kalmadan çözümlenebilir veya alandaki yapının çerçevelerinin ve donatıların koyu gri olmasından dolayı gri renkte bir döşeme seçilerek ikincil bir renge ihtiyaç kalmayabilir.

\section{3 - Geleneksellemiş Çim Taşı}

Her bahçede olduğu gibi minimalist bahçelerde de mükemmel bir yüzey malzemesi olarak çim kullanılır. Biçilmiş ya da biçilmemiş olsun, çim, ahşap ve taş yüzeylerle kolayca birleşebilen nötr bir taban oluşturur.

\section{4 - Sınırlı Bitki Paleti Kullanımı}

Bitkiler minimalist bahçelerde sert zemin peyzajını yumuşatmak amacıyla kullanılır. Bu yüzden de fazla bitki bloğuna ihtiyaç olmayabilir. Paletle kullanılan bitkiler daha iyi görünürler ve daha kolay bakımları vardır. Buxus spp. minimalist bahçeler için en sevilen seçenektir. Her daim yeşil yaprakları, yıl boyu tek renk seçeneği sunar ve keskin şekiller verilebilir. Minimalist bahçelerde budanabilen, şekil verilebilen, gri ve asit yeşili yani monokromatik (siyahgri-asit yeşili) renkli bitkiler kullanılır.

\section{5 - Bitki Paleti ve Saksı Uyumu}

Hem konteyner (saksı) seçimi hem de sınırlı bir bitki paletinin kullanılmasıyla uyumlu bir renk kombinasyonu oluşturulmalıdır. Kaplar çağdaş, şık ve temiz bir yüzeye sahip olmalıdır. Çağdaş tarlalar bu duruma bir örnek sayılabilir.

\section{6 - Kontrollü Ses ve Hareket}

Minimalist bahçelerde su özellikleri ve kullanımları sınırlıdır. Süs özelliğinden daha çok genel düzenin bir parçası olmaları prensibi gözetilir. Sağladıkları hareket dahi bir sakinlik hissi oluşturmalıdır.

Sonuç olarak; minimalist bir bahçenin iyi bir şekilde yürütülen, detaylandırılmış güçlü bir çizgiye sahip ve net bir amacı olmalıdır. Minimalist bahçenin doğru tasarlanması yeterli değildir aynı zamanda işçilik de kaliteli olmalıdır. 
Minimalist bahçeler modern yaşamın streslerine karşı mükemmel bir panzehir özelliği gösterir. Aileniz için geniş, huzurlu ve az bakım gerektiren bir bahçe ile son bulur [25].

\section{Minimalizm;}

1. Sık dokuda ve yoğun bir plantasyon gerektirmediği için yangın ve hastalıkların yayılmasını engellemektedir.

2. Görsel bir kalite sunmaktadır.

3. Psikolojik rahatlık sağlamaktadır.

4. Dar alanda peyzaj tasarım ve uygulamaları sağlamaktadır.

5. Donatı malzemelerinin görsel uyumluluk ve uyum kalitesini arttırmaktadır.

6. Eski moloz, ahşap vb. materyalleri tekrar kullanım imkânı sağlayarak sürdürülebilirlik sağlamaktadır.

7. Enerji tasarrufu sağlar. Yerli ve endemik bitkiler kullanılarak su, az materyal kullanarak ekonomik, kısa sürede inşa edilerek zaman tasarrufu sağlamaktadır.

8. Geniş ve ferah alanlar sağladığından, aydınlatma ve yansıma daha rahat olmaktadır.

9. Minimalizm sadece çizgisel bir akım değil daha ötesinde kompozisyon, konstrüksiyonel materyallerin fonksiyonel kullanımı önceliklidir.

10. Güçlü kütlesel formları kullanmakta ve bu formlarla insan psikolojisi üzerinde büyük etkiler uyandirmaktadır.

11. Minimal çerçevede gerçekleşen, geleneksel ya da modernist disiplinler ve akımlarla işbirliği kurmaktadır.

12. Gelenek ile modern ve post-modernist akımların bir arada kullanıldığı aracı bir akım olarak, ortak bir zemin hazırlamaktadır.

13. Bitki parterleri veya ağaçları soliter olarak (bir nevi heykel gibi) kullanıldığında bir sergi özelliği gösterirken, toplu ve düzenli olarak kullanıldığında rehabilite (veya rahatlama) etkisi göstermektedir.

5. Kaynaklar

[1] Taşdemir, D., “Çağdaş Peyzaj Mimarlarının Yaklaşımları Çerçevesinde Peyzaj Mimarlığının Gelişim Süreci” Yüksek Lisans Tezi, Ankara, 2010

[2] Islakoğlu, M., “Minimalizm Kavramı ve Mimarlıkta Minimalist Yaklaşımlar” Aralık, İzmir, 2006

[3] Elgün, T., “Bir Akım Olarak Minimalizm” Adam Sanat Dergisi, Sayı 126, Mayıs, İstanbul, 1996

[4] Köksal, A., “Minimalist Ressam Ve Bir Besteci: Stella ve Glass” Ankara Üniversitesi Dil ve Tarih-Coğrafya Fakültesi Dergisi, Sayı 47, s.31-42, Ankara, 2007

[5] Döl, A.; Avşar, P., “Minimalizim Akımı Kapsamında Nesne Anlayışının Yeniden Değerlendirilmesi” İdil, Cilt 2, Say1 10, s.1-18, 2013

[6] Şahbaz, H., “Modern Seramik Sanatında Minimalizm” Anadolu Üniversitesi, Sosyal Bilimler Enstitüsü, Yüksek Lisans Tezi, s.129, Eskişehir, 2006

[7] Aydoğdu Ünlü, S. A., “Cumhuriyet Dönemi Kentsel Açık Alanlarının Sanat Akımları Açısından İncelenmesi Üzerine bir Araştırma İstanbul Örneği” IÜ Fen Bilimleri Enstitüsü, Basılmamış Yüksek Lisans Tezi, İstanbul, 2007

[8] Kirby, L., “Contemporary Landscape Architecture History” Arkansas University, USA, 2009 
Nevşehir Bilim ve Teknoloji Dergisi (2019), 8(Enar Özel Sayı) 89-103

[9] Campbell, K., “Icons of Twentieth Century Landscape Design” 166p, USA, 2007

[10] Amidon, J., “Radical Landscapes: Reinventing Outdoor Space” Thames \& Hudson Ltd., London, 2001

[11] Akay, A., “Sanat Tarihi Sıradışı Bir Disiplin” Y.K.Y., s.64, İstanbul, 2009

[12] Antmen, A., “20.YY. Batı Sanat Akımları” (1.Bask1), Sel Yayıncılık, s.182, İstanbul, 2008

[13] O'Doherty, B., “Beyaz Küpün İçinde Galeri Mekânının İdeolojisi” Sel Yayıncılık, s.17, İstanbul, 2010

[14] Erzen, J. N., “Minimalizm” Eczabaşı Sanat Ansiklopedisi II, s.1260, 1997

[15] Kavukcu, E., “Minimal Bir Yaklaşımla Çözümsel Bir Arayış; Yalınlaştırma” Atatürk Üniversitesi, Sosyal Bilimler Enstitüsü, Yüksek Lisans Tezi, s.72, Erzurum, 2012

[16] Little, S., “İzmler Sanatı Anlamak” Yem Yayınlarl, s.139, İstanbul, 2010

[17] Yılmaz, M., “Sanatçıları Okumak ya da Postmodern Söyleşiler” Ütopya Yayınları, Ankara, 2006

[18] Anonymous, 2017. Web sitesi: http://www.felsefeekibi.com, Erişim Tarihi: 15.11.2017.

[19] Anonymous, 2017a. Web sitesi: http://www.tr.wikipedia.org, Erişim Tarihi: 21.11.2017

[20] Anonymous, 2017b. Web sitesi: http://www.swagroup.com, Erişim Tarihi: 23.11.2017

[21] Anonymous, 2017c. Web sitesi: http://www.arkitera.com, Erişim Tarihi: 01.12.2017

[22] Anonymous, 2017d. Web sitesi: http://www.gardenvisit.com, Erişim Tarihi: 05.12.2017

[23] Anonymous, 2017e. Web sitesi: http://www.arkiv.com.tr, Erişim Tarihi: 15.12.2017

[24] Anonymous, 2017f. Web sitesi: https://www.houzz.com, Erişim Tarihi: 16.12.2017

[25] Anonymous, 2014. https://www.houzz.co.uk/magazine/gardens-how-to-design-a-calming-minimalist-gardenstsetivw-vs 27788514, Erişim Tarihi: 24.03.19 


\section{Extended Abstract}

\section{Introduction}

Art; it is a collection of actions that are carried out for the transfer of emotion and thought as anti-pragmatist, with great skill. With these developments and changes, art movements occurred according to periods. While the artistic activities in the process that existed until the beginning of the 20th century were known as the Traditional Art Movements, they had undergone great changes under the name of Modernism (Contemporary Art Movements) since the beginning of the 20th century. World War II; that is, after 1960, it is known as Post-Modernism.

Traditional styles have been influential in landscape architecture until the beginning of the 20th century. During this period, more naturalistic and picturesque style and formal or informal designs were applied. At the beginning of the 20th century, there were modernists who settled outside the tradition in art and architecture, and even settled in the history of the past, completely rejecting this traditionality. After the 1920s, the modern architecture began to dominate modern architecture.

Beside the scientific and technical stages, functional and spatial solutions were presented in landscape designs and the use of new materials was provided by using technology. Considering human life satisfaction with this process, environmentally sensitive and ecological approaches have been realized.

Minimalism; The word minimalism derives from the French word for minimal, a minimum meaning. The meaning of the word is defined as the minimum or minimum quantity (degree, quantity) required for a need or individual. First, Minimalism was first used by Richard Wolheim in 1965. It is a minimalist picture with a simple, geometric design that emerges as large areas of monochrome color where a few limited colors are used.

Visual arts, music, literature, philosophy, education techniques, computer software and architecture, which is the main feature of this current flow is to minimize the material. To give a visual impression in minimalist designs; hard edges, geometric, large, simple forms are given. It is believed that the basic forms of a square, rectangle or circle inevitably give rise to certain emotions in the viewer. Reductive attitude was exhibited in terms of color and form. Due to the mental fatigue of the society and stress filled, it does not require intervention to its natural colors and tissues; wood, concrete, steel, iron, ready-to-use materials such as industrial products.

It has started to be seen in contemporary landscape architecture especially after 1960s. The Minimalism movement emphasizes the concept of simplicity, simplicity and lowness from landscape architecture, while it includes simple geometric forms and pure colors. He did not upload or add designs to a design. Integrity and perfectionism in simplicity are dominant. The aim of minimalism in landscape architecture is to reveal the most functional result with the least material, the simplest and most economical at the same time.

In addition, minimalism offers an artistic and successful movement against the huge wastes and diminishing resources which are currently the most important environmental problems we face.

\section{Method}

The material of the study, examined in Turkey apart from 13 different countries and different from nearly 30 cities periods were the photos taken from the landscape and viewed from various cities in Turkey were landscape design with is the work which made the design as a minimalist visual arts and architecture. Based on these examples, minimalist design criteria in landscape architecture have been established.

Within the scope of the study, the basic philosophy, characteristics, current status and criteria of the minimalism movement in architecture and visual arts have been put forward. Then, the designs made within the scope of minimalist movement were examined. In the last stage; As a result of land surveys conducted in different countries, the common characteristics of the designs that could be minimalist design in terms of landscape architecture were determined and the basic criteria of this art movement in the landscape architecture discipline were determined.

In this context, especially in visual arts emphasizing minimalist design; [3], [4], [5], [6], [11], [12], [13], [14], [15], [16], [17] from the sources and on the minimalist approach in the field of landscape [1], [2], [7], [8], [9] and [10].

\section{Results and Discussion}

Minimalism;

1. Prevents the spread of fire and diseases since it does not require a dense plantation and frequent texture.

2. Offers a visual quality.

3. Provides psychological comfort. 
4. It provides landscape design and applications in narrow space.

5. Improves the visual compatibility and quality of the reinforcement materials.

6. Old rubble, wood etc. provides sustainability by reusing materials.

7. Energy saving. By using local and endemic plants, water is economically used by using less material and it is built in a short time and saves time.

8. Since it provides large and spacious areas, lighting and reflection are more comfortable. 